\title{
Acompanhamento nutricional de criança portadora de anemia falciforme na Rede de Atenção Básica à Saúde
}

\author{
Nutritional follow-up of children with sickle cell anemia treated in a Primary Care Unit
}

Karen Cordovil M. de Souza ${ }^{1}$, Jorginete de Jesus Damião², Kamile Santos Siqueira ${ }^{3}$, Lilian Carissa S. dos Santos ${ }^{1}$, Mariana Rosa dos Santos ${ }^{1}$

\section{RESUMO}

Objetivo: Relatar estudo de caso de atendimento nutricional a criança com diagnóstico de anemia falciforme.

Descrição do caso: Realizaram-se quatro atendimentos nutricionais pela equipe do Internato de Nutrição da Universidade do Estado do Rio de Janeiro (Uerj) no período de julho a setembro de 2005 a criança de 1 a 4 meses, feminina, negra, com anemia falciforme. $\mathrm{Na}$ avaliação do estado nutricional e do ganho de peso, empregaram-se os seguintes indicadores antropométricos: comprimento/idade, peso/idade e peso/comprimento, e um indicador de impacto nutricional. A análise dietética compreendeu a avaliação da ingestão energética e de macronutrientes observada na primeira consulta após 30 dias de intervenção.

Comentários: Ao longo do período analisado, a baixa estatura para a idade $(z=-1,32)$ evoluiu para adequação $(z=0,87)$, enquanto o peso em relação ao comprimento manteve-se inadequado $(z=-2,53)$. O ganho de peso foi $50 \%$ inferior ao incremento esperado. $\mathrm{O}$ consumo energético inicialmente inadequado (60\% das recomendações) alcançou, após 30 dias, $117 \%$. A Estratégia em Saúde da Família vem sendo recomendada como importante ferramenta para monitorar as condições nutricionais, bem como para melhorar a atenção prestada. Entretanto, considerando o modelo de atenção primária local, observa-se haver necessidade de capacitação, especialmente no que tange às peculiaridades inerentes à condição de nutrição e de saúde dos portadores de anemia falciforme.
Palavras-chave: anemia falciforme; estado nutricional; crescimento; ganho de peso; insuficiência de crescimento.

\section{ABSTRACT}

Objective: To report the nutritional follow-up of a black baby girl, one year and four months old, with homozygous sickle cell anemia.

Case description: From July-September 2005, the infant attended four nutritional appointments at the Nutrition Internship Program from the State University of Rio de Janeiro, Rio de Janeiro, Brazil. The nutritional status was evaluated by the anthropometric indexes: length/age, weight/age and weight/length, and by one indicator of nutritional impact. Analysis of the energy dietary intakes and macronutrients ingestion was performed in two opportunities: at the first nutritional evaluation and 30 days after the first intervention.

Comments: At the first nutritional evaluation, the child presented low stature/age $(\mathrm{z}=-1,32)$, that became adequate during the follow-up $(\mathrm{z}=0,87)$. The low weight/length $(z=-2,53)$ was similar at the first and final evaluations. The weight gain during the follow-up period was only $50 \%$ of the expected increment. The energy dietary intake was $66 \%$ of the recommended energy intake at the first appointment and $117 \%$ after 30 days. The Family Health Strategy is recommended as an important tool to monitor nutritional status and improve nutritional care. There is a need of developing
Instituição: Universidade do Estado do Rio de Janeiro (Uerj), Rio de Janeiro, RJ, Brasil

${ }^{1}$ Nutricionista, ex-aluna do Instituto de Nutrição da Uerj. Rio de Janeiro, RJ, Brasil

${ }^{2}$ Mestre em Saúde Pública, professora-assistente do Departamento de Nutrição Social do Instituto de Nutrição da Uerj, Rio de Janeiro, RJ, Brasil ${ }^{3}$ Doutora em Saúde Coletiva, ex-professora substituta do Departamento de Nutrição Social do Instituto de Nutrição da Uerj, sanitarista da Secretaria de Estado de Saúde e Defesa Civil do Rio de Janeiro, Rio de Janeiro, RJ, Brasil
Endereço para correspondência:

Jorginete de Jesus Damião

Rua São Francisco Xavier, 524 - Pavilhão João Lyra Filho, $12^{\circ}$ andar, bloco $\mathrm{D}$, sala 12.024

CEP 20550-013 - Rio de Janeiro/RJ

E-mail: jjdamiao@yahoo.com ou karensouz@gmail.com

Recebido em: 19/2/2008

Aprovado em: 2/7/2008 
professional skills regarding nutritional care of patients with sickle cell anemia.

Key-words: anemia, sickle cell; nutritional status; growth; weight gain; failure to thrive.

\section{Introdução}

A ocorrência de atraso no crescimento e desenvolvimento em pacientes com anemia falciforme tem sido relatada na literatura e observada na prática clínica. $\mathrm{O}$ atraso da maturação óssea nesse grupo aumenta progressivamente com a idade. No entanto, a época em que tal atraso se inicia não está bem estabelecida ${ }^{(1)}$.

Em crianças com anemia falciforme, o metabolismo está muito acelerado em função da hemólise crônica, da anemia e de fenômenos vaso-oclusivos. Mesmo em períodos sem crises ou complicações, as necessidades de proteína, energia e minerais são elevadas ${ }^{(2)}$.

Vários fatores influenciam no déficit de crescimento, tais como as disfunções endócrinas, o baixo consumo alimentar, os requerimentos energéticos aumentados e a baixa condição socioeconômica ${ }^{(3)}$. Por essas razões, os pacientes tendem a ser desnutridos e a ter frequentemente déficit de estatura, de peso e de maturação esquelética ${ }^{(4)}$.

A Organização Mundial da Saúde (OMS) estima que anualmente nasçam no Brasil cerca de 2.500 crianças com doença falciforme, das quais aproximadamente 1.900 têm a anemia falciforme ${ }^{(5)}$. A Estratégia de Saúde da Família desempenha papel fundamental nas ações de caráter primário aos pacientes com doença falciforme. Nessa perspectiva, relata-se o caso de uma criança portadora de anemia falciforme. Propõe-se um método de avaliação e acompanhamento do estado nutricional e da ingestão alimentar na Atenção Básica de Saúde.

\section{Relato do caso}

Os dados foram coletados no período de julho a setembro de 2005, a partir de atendimentos realizados por uma equipe composta de alunas de nutrição da Universidade do Estado do Rio de Janeiro (Uerj), integradas à Equipe de Saúde da Família do município de Casimiro de Abreu, Rio de Janeiro. A anamnese alimentar e a conduta nutricional descritas referem-se a quatro consultas de nutrição com periodicidade quinzenal. As informações foram coletadas do prontuário da unidade e de impressos específicos da equipe de Nutrição.
Solicitou-se o consentimento do responsável pela criança para que o relato de caso fosse descrito, assegurando-se de que a criança não teria sua identidade revelada. Trata-se de uma criança atendida pela primeira vez em julho de 2005, com 16 meses de idade, de sexo feminino, negra, com peso ao nascimento de $2.100 \mathrm{~g}$ e diagnóstico de baixo peso para a idade. Tal diagnóstico foi feito por uma equipe de agentes comunitários de saúde que a encaminhou para consulta médica e de nutrição.

A mãe relatou que a criança era portadora de anemia falciforme em acompanhamento em hospital especializado da rede pública. A perda de peso de $300 \mathrm{~g}$ nos últimos dois meses foi o motivo da consulta. A criança fazia uso diário de ácido fólico, sem relato de crises vaso-oclusivas ou transfusões de hemácias. Ressalta-se que, até então, a criança não apresentava registros no prontuário da família e não portava resultados de exames laboratoriais ou outros relatos do acompanhamento feito no Instituto Estadual de Hematologia Arthur de Siqueira Cavalcanti.

$\mathrm{Na}$ consulta subseqüente, realizou-se anamnese alimentar e orientação nutricional personalizada. A criança apresentava temor e choros freqüentes. A mãe relatou que o aleitamento materno foi exclusivo até três meses de idade. Atualmente, fazia uso de mamadeira, ingestão de preparações com baixa densidade energética, predominância de refeições lácteas, horários irregulares e inadequação das quantidades de alimentos oferecidos. Elaborou-se um plano alimentar com redefinição da quantidade de alimentos nas pequenas refeições, sua composição e horários, além de se introduzirem alimentos de maior densidade energética nas grandes refeições. Procurou-se desencorajar o uso de mamadeira, sugerindo-se a troca por copo ou prato. Houve também orientação para prevenir a desidratação infantil e esclarecimento sobre o comprometimento do estado nutricional na doença falciforme, visto que a mãe não demonstrava estar informada sobre o assunto. $\mathrm{O}$ retorno da paciente foi agendado para 15 dias.

$\mathrm{Na}$ consulta de retorno, a mãe relatou ter seguido as orientações fornecidas sem dificuldades, observando-se um discreto aumento de peso $(7,72 \mathrm{~kg}$ versus $7,66 \mathrm{~kg}: 60 \mathrm{~g})$. Nessa consulta, foram reiteradas as orientações do primeiro atendimento. Em novo retorno, após novos 15 dias, a mãe relatou continuar oferecendo mamadeiras e sopas à criança, mas com menor freqüência. Como conduta, foi informada a quantidade de leite de vaca para o mingau introduzido no plano alimentar e foi proposto à mãe que a paciente se integrasse ao programa da unidade para crianças em risco nutricional para receber assistência complementar. 


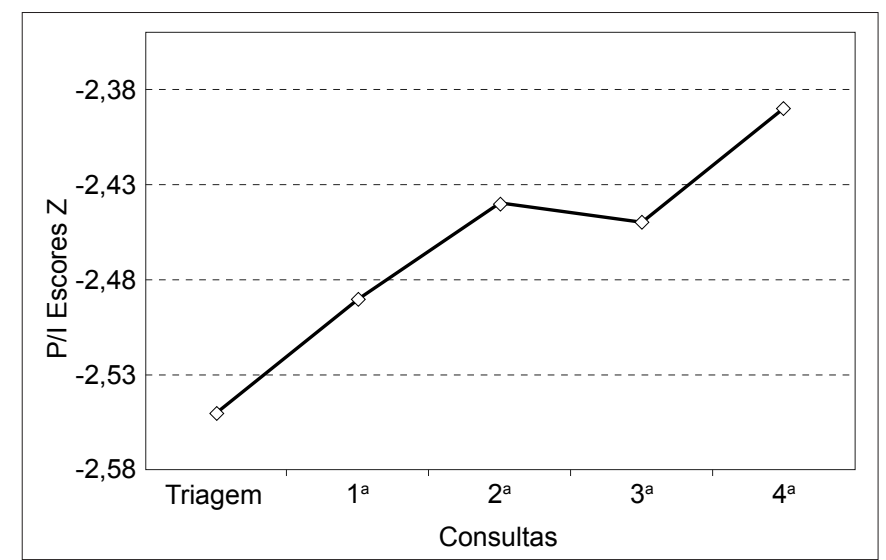

Gráfico 1 - Valores de escores Z para o indicador massa corporal para idade de criança com anemia falciforme, no período de intervenção nutricional.

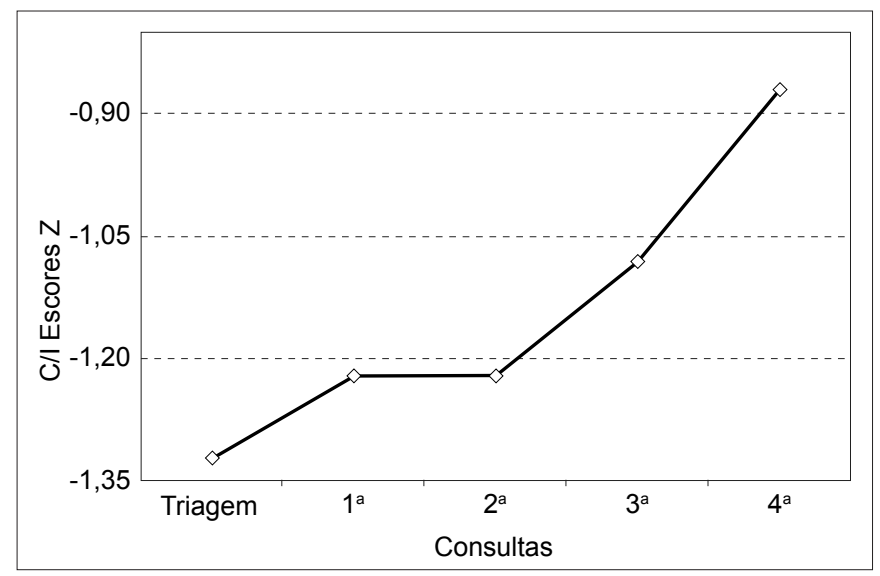

Gráfico 2 - Valores de escores Z para o indicador comprimento para idade de criança com anemia falciforme, no período de intervenção nutricional.

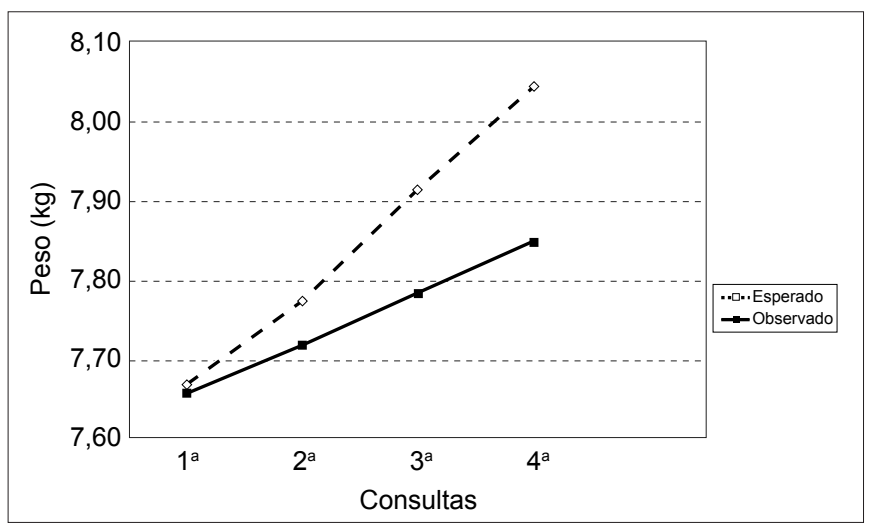

Gráfico 3 - Avaliação do ganho de peso de criança com anemia falciforme. Comparação entre o incremento esperado e o observador, segundo sexo e idade.
Por fim, na consulta seguinte, cerca de dois meses após a inicial, a equipe de nutrição orientou a mãe quanto ao preparo das refeições, visando aumentar a densidade energética e a ingestão de líquidos em períodos de gripes e resfriados. $\mathrm{Na}$ ocasião, a mãe estava seguindo o plano alimentar proposto e se mostrou mais confiante em relação às orientações e com melhor entendimento.

A aferição antropométrica de peso e comprimento foi realizada segundo padronização proposta por Lohman ${ }^{(6)}$. Em todas a consultas, o peso foi medido em balança mecânica pediátrica, com capacidade de $16 \mathrm{~kg}$, e o comprimento com antropômetro horizontal com precisão de $1 \mathrm{~mm}$. A avaliação do estado nutricional foi realizada por meio dos indicadores antropométricos: peso para idade $(\mathrm{P} / \mathrm{I})$, peso para comprimento $(\mathrm{P} / \mathrm{C})$ e comprimento para idade $(\mathrm{C} / \mathrm{I}$,) descritos em percentis e em escore $Z^{(7)}$, com pontos de cortes preconizados pelo $\mathrm{Na}$ tional Center for Health Statistics (NCHS), de acordo com o Ministério da Saúde do Brasil ${ }^{(8)}$. As relações P/I e C/I podem ser observadas nos Gráficos 1 e 2 .

No Gráfico 1, observa-se, a partir do indicador P/I, um baixo peso para a idade muito acentuado ao longo das primeiras consultas, com discreta melhora ao final dos dois meses de intervenção. Entretanto, mesmo na quarta consulta consecutiva, a criança continuava apresentando ganho de peso insuficiente para sua idade $(z=-2,39)$. No acompanhamento do $C / I$, apresentado na Figura 2, nota-se que a criança apresentava baixo comprimento para idade $(\mathrm{z}=-1,32)$, evoluindo para um estado de adequação $(z=-0,87)$. De acordo com o indicador $\mathrm{P} / \mathrm{C}$, houve queda nos valores de escore $Z$ da primeira para a última consulta (dados não apresentados). Observou-se, assim, variação positiva do estado nutricional avaliado por meio do indicador $\mathrm{C} / \mathrm{I}(\Delta \mathrm{z}=0,46)$ e variação quase nula do estado nutricional avaliado por meio do indicador $\mathrm{P} / \mathrm{I}(\Delta \mathrm{z}=0,16)$.

Durante o acompanhamento, utilizou-se a matriz do incremento de peso segundo o sexo e a idade, proposto por Castro $^{(9)}$ para avaliar o ganho de peso, sendo descartados os dados da primeira consulta ${ }^{(9,10)}$. Tal matriz foi empregada para comparar a diferença entre os valores medianos de peso segundo idade e sexo da população de referência ${ }^{(10)}$ (ganho de peso esperado) no período de interesse.

Os valores de ganho de peso observado e esperado (matriz) foram comparados no período da intervenção (Tabela 1). A adequação do incremento observado em relação ao esperado foi em torno de $50 \%$. Essa diferença foi maior entre o primeiro e o segundo períodos avaliados $(20 \mathrm{~g})$, em relação ao segundo e terceiro períodos ( $10 \mathrm{~g})$. O Gráfico 3 mostra a evolução do quadro ao longo das consultas. Observou-se um 
Tabela 1 - Valores de incremento de peso esperado e observado e adequação de incremento de peso e déficit de incremento observados na criança estudada, no período da intervenção nutricional

\begin{tabular}{lcccc}
\hline Consultas & $\begin{array}{c}\text { Incremento } \\
\text { esperado }\end{array}$ & $\begin{array}{c}\text { Incremento } \\
\text { observado }\end{array}$ & Adequação & $\begin{array}{c}\text { Déficit de } \\
\text { incremento }\end{array}$ \\
\hline $1^{\circ}-2^{\circ}$ & $105 \mathrm{~g}$ & $60 \mathrm{~g}$ & $57 \%$ & $-45 \mathrm{~g}$ \\
$2^{\circ}-3^{\circ}$ & $140 \mathrm{~g}$ & $65 \mathrm{~g}$ & $47 \%$ & $-75 \mathrm{~g}$ \\
$3^{\circ}-4^{\circ}$ & $130 \mathrm{~g}$ & $65 \mathrm{~g}$ & $50 \%$ & $-65 \mathrm{~g}$ \\
\hline
\end{tabular}

Tabela 2 - Comparação do gasto energético total (VET em Kcal) entre três recomendações diferentes no início e após a intervenção nutricional

\begin{tabular}{|c|c|c|c|c|c|c|}
\hline \multirow[t]{2}{*}{ Intervenção } & \multirow[t]{2}{*}{ Idade } & \multirow{2}{*}{$\begin{array}{c}\text { FAO/OMS } \\
1985\end{array}$} & \multirow{2}{*}{$\begin{array}{c}\text { FAO/OMS } \\
2001\end{array}$} & \multicolumn{2}{|c|}{ Monte, 2002} & \multirow[t]{2}{*}{ Adequação } \\
\hline & & & & Referência & Observado & \\
\hline Início & 1a $4 \mathrm{~m}$ & 965 & 884 & 1.379 & 916 & $66 \%$ \\
\hline Após & 1a $5 \mathrm{~m}$ & 981 & 893 & 1.401 & 1.633 & $117 \%$ \\
\hline
\end{tabular}

Obs.: os pesos referentes ao início e após 30 dias de intervenção nutricional foram respectivamente 7,76kg e 7,79kg. A atividade física foi considerada como leve.

distanciamento da curva de incremento de peso apresentado pela criança em comparação à curva observada na população de referência.

Foram realizadas duas avaliações de ingestão alimentar em consultas não consecutivas, na primeira consulta e após 30 dias. Analisou-se, por meio da anamnese alimentar, o consumo de energia e de macronutrientes (carboidratos, lipídeos e proteínas). A quantificação dos nutrientes foi realizada com o auxílio das tabelas de composição de alimentos de Pinheiro ${ }^{(11)}$ e Philippi ${ }^{(12)}$. O gasto energético total foi calculado a partir das referências da Food and Agriculture Organization/Organização Mundial da Saúde/Organização das Nações Unidas (FAO/OMS/ONU) ${ }^{(13)}$ e $\mathrm{FAO}^{(14)}$, com base em medidas reais e estimativas de energia, considerando o gasto total, a necessidade para o crescimento e a recomendação de Monte ${ }^{(15)}$ que estipula uma oferta calórica de $150-220 \mathrm{kcal} / \mathrm{kg} / \mathrm{dia}$ para crianças desnutridas. Tanto para o cálculo pela $\mathrm{FAO} / \mathrm{OMS} / \mathrm{ONU}^{(13)}$ como pela $\mathrm{FAO}^{(14)}$ foi acrescido $20 \%{ }^{(1,2)}$ à taxa metabólica basal devido à desnutrição. Para o cálculo proposto por Monte ${ }^{(15)}$, utilizou-se $180 \mathrm{kcal} / \mathrm{kg} / \mathrm{dia}$, valor médio da faixa recomendada. Tais dados estão apresentados na Tabela 2. A equação proposta por Monte sugeria um gasto energético maior e, portanto, mais adequado à pretensão de recuperação de ganho de peso. A ingestão energética pela equação de Monte mostrou uma adequação da ingestão energética de $66 \%$ no início do acompanhamento e de $117 \%$ após 30 dias.
Quanto à análise de macronutrientes, observou-se um aumento no consumo de carboidratos, proteínas e manutenção no consumo de lipídeos. Em relação à ingestão de proteína, foi possível atingir a recomendação proposta por Monte ${ }^{(15)}$ para crianças desnutridas (4 a $6 \mathrm{~g} / \mathrm{kg} / \mathrm{dia}$ ). O consumo de zinco passou de $40,5 \%$ da Dietary Reference Intake (DRI) (16) para $145 \%$ de adequação após 30 dias.

\section{Comentários}

O crescimento é um dos melhores indicadores de saúde da criança e é imprescindível na avaliação de pacientes com doença falciforme, uma vez que, neste grupo, o fator genético tem grande influência. Dependendo do genótipo e haplótipo, haverá maior grau de catabolismo e tendência às complicações secundárias à doença.

Lowry et $a l^{(17)}$ observaram tendência de baixo peso em pacientes com muitas admissões hospitalares. Neste trabalho, não houve relatos de internação por vaso-oclusões.

Um déficit de estatura crônico pode ser irreversível e prejudicial ao potencial genético de crescimento caso não haja intervenção oportuna. A intervenção descrita teve impacto no déficit de estatura. Um estudo feito com crianças brasileiras mostrou que pacientes homozigotos (SS) apresentavam maior déficit na estatura, progressivo com a idade, comparados a indivíduos com hemoglobinas traço (AS) e normal (AA) ${ }^{(18)}$. Ressalta-se, contudo, que a 
altura final na idade adulta não é prejudicada, visto que o fechamento epifisário também é mais tardio, o que permite a recuperação da estatura.

O peso ao nascimento das crianças com anemia falciforme é normal ${ }^{(2)}$, porém, as alterações nesse parâmetro se manifestam já no final do primeiro ano de vida. Neste estudo, observouse pequeno ganho de peso da criança. Entretanto, a evolução ponderal nas últimas consultas foi superior à ocorrida no início da intervenção.

Nas consultas realizadas, foram reforçadas, para a mãe, questões sobre a alimentação da criança a fim de que a ingestão e a densidade energética das preparações fossem aumentadas, pois o consumo alimentar na infância está intimamente associado ao perfil de saúde e nutrição, principalmente em crianças menores de dois anos de idade ${ }^{(19)}$. A anemia falciforme provoca maior demanda metabólica, mas não há registro de métodos e equações específicas de uso ambulatorial para se medir ou estimar o gasto energético da doença falciforme em Pediatria.

A deficiência de zinco nos pacientes com anemia falciforme ainda não é bem esclarecida ${ }^{(20,21)}$, mas está relacionada

\section{Referências bibliográficas}

1. Stopler T. Terapia nutricional para anemia. In: Mahan LK, Escott-Stump S, editors. Krause, Alimentos, Nutrição e Dietoterapia. $11^{\mathrm{a}}$ ed. São Paulo: Roca; 2005. p. 816-7.

2. Carneiro J, Murad Y. Crescimento e Desenvolvimento. In: Agência Nacional de Vigilância Sanitária, editor. Manual de Diagnóstico e Tratamento para Doenças Falciformes. Brasília: Anvisa; 2002. p. 77-82.

3. Barden EM, Kawchak DA, Ohene-Frempong K, Stallings V, Zemel B. Body composition in children with sickle cell disease. Am J Clin Nutr 2002;76:218-25.

4. Singhal $A$, Parker S, Linsell L, Serjeant $G$. Energy intake and resting metabolic rate in preschool Jamaican children with homozygous sickle cell disease. Am J Clin Nutr 2002;75:1093-7.

5. Diniz D, Guedes C. Confidentiality, genetic counseling, and public health: a case study on sickle cell trait. Cad Saude Publica 2005;21:747-55.

6. Lohman TG, Roche AF, Martorell R, editors. Anthropometric standardization reference manual. Champaign: Human Kinetics Books; 1988.

7. Ashworth A, Khanum S, Jackson A, Shofield C, editors. Guidelines for the inpatient treatment of severely malnourished children. Geneva: WHO; 2003.

8. Brasil. Ministério da Saúde. Portal da Saúde. [homepage on the Internet]. Índices das tabelas do NCHS. National Centers for Health Statistic. Brasília: Ministério da Saúde, 2004 [cited 2008 Jun 04]. Available from: http://dtr2004. saude.gov.br/nutricao/documentos/tabela_completa.pdf

9. Castro IR. Efetividade da suplementação alimentar na recuperação de crianças desnutridas: avaliação do Programa "Leite é Saúde" no município do Rio de Janeiro [tese de doutorado]. São Paulo (SP): Faculdade de Saúde Pública, USP; 1999.

10. Brasil. Secretaria Municipal de Saúde. Instituto Annes Dias. Avaliação da Evolução de Ganho de Peso das Crianças em Risco Nutricional: Indicador de Impacto Nutricional. Rio de Janeiro: Secretaria Municipal de Saúde; 2003.

11. Pinheiro AB, Lacerda EM, Benzecry EH, Gomes MC, Costa VM, editors. Tabela para avaliação de consumo alimentar em medidas caseiras. $4^{\mathrm{a}}$ ed. São Paulo: Atheneu; 2001. ao retardo do crescimento ${ }^{(22)}$. Houve recuperação favorável da ingestão de zinco, concomitante à melhoria no indicador de comprimento/idade.

A mãe mostrou desconhecimento dos fatores relacionados ao cuidado da criança que poderiam ter influência no prognóstico da doença e na evolução do estado nutricional. Quanto à adesão às orientações nutricionais, observou-se que esteve relacionada ao vínculo criado a partir do segundo encontro.

No Brasil, a composição corporal, os hábitos alimentares e as interações entre nutrientes na anemia falciforme não foram muito estudados. Ressalta-se que há uma gama de doenças genéticas e de erros inatos do metabolismo que desafia o profissional preocupado com a saúde alimentar de tais pacientes.

O acompanhamento por Equipe de Saúde da Família é uma estratégia válida para a melhoria da atenção prestada a este grupo, que tanto sofre com fatores ambientais e intrínsecos à doença crônica. A abordagem nutricional das doenças falciformes requer capacitação e treinamento dos profissionais que prestam atenção básica à saúde.

12. Philippi ST, editor. Tabela de composição de alimentos: suporte para decisão nutricional. $2^{a}$ ed. São Paulo: Coronário; 2002

13. FAO/OMS/ONU. Necessidades de energia e de proteínas. Genebra: OMS 1985.

14. Food and Agriculture Organization (FAO). Energy Requirements of Children and Adolescents. In: FAO, editor. Human Energy Requirements. Rome: FAO; 2001. p. 28-103.

15. Monte CM. Atendimento a criança desnutrida em ambulatório e comunidade. In: Departamento de Nutrição da Sociedade Brasileira de Pediatria, editor. Temas de nutrição em pediatria. Rio de Janeiro: Sociedade Brasileira de Pediatria; 2002. p. 13-22.

16. Food and Nutrition Board, Institute of Medicine. Dietary reference intake for vitamin $\mathrm{A}$, vitamin $\mathrm{K}$, arsenic, boron, chromium, copper, iodine, iron, manganese, molybdenum, nickel, silicon, vanadium and zinc. Washington, DC: National Academy Press; 2001.

17. Lowry MF, Desai P, Ashcroft MT, Serjeant BF, Serjeant GR. Heights and weights of Jamaican children with homozygous sickle cell disease. Hum Biol 1977;49:429-36.

18. Braga JA, Kerbauy J, Fisberg M. Zinc, copper and iron and their interrelations in the growth of sickle cell patients. Arch Latin Nutr 1995;45: 198-203.

19. Oliveira LP, Assis AM, Pinheiro SM, Prado MS, Barreto ML. Alimentação complementar nos primeiros dois anos de vida. Rev Nutr 2005;18:459-69.

20. Prasad AS. Zinc deficiency in patients with sickle cell disease. Am J Clin Nutr 2002;75:181-2.

21. Zemel BS, Kawchak DA, Fung EB, Ohene-Frempong K, Staliings VA. Effect of zinc supplementation on growth and body composition in children with sickle cell disease. Am J Clin Nutr 2002;75:300-7.

22. Phebus CK, Maciak BJ, Gloninger MF, Paul HS. Zinc status of children with sickle cell disease: relationship to poor growth. Am J Hematol 1988;29: 67-73. 